
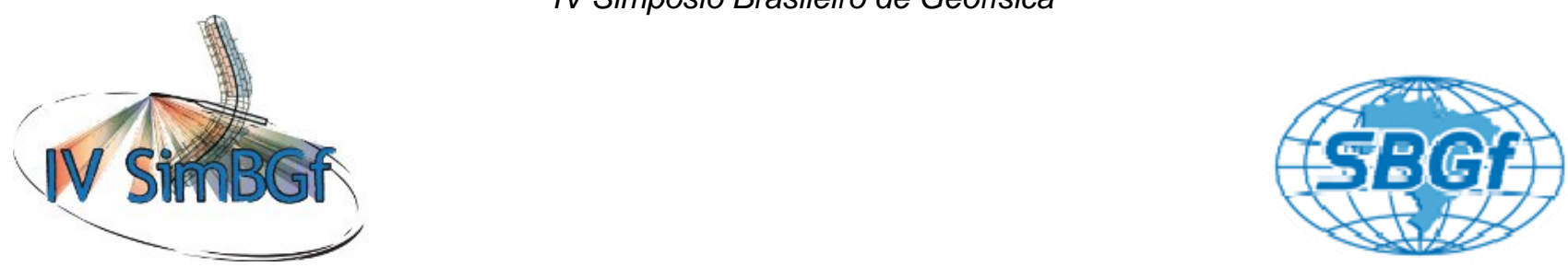

\title{
Análise de velocidade PSTM aplicada em dados sísmicos da Bacia do Tacutu
}

\author{
Carlos Jesus, Geokinetics/ Dra. Eliane Alves UFF
}

Copyright 2010, SBGf - Sociedade Brasileira de Geofísica

Este texto foi preparado para a apresentação no IV Simpósio Brasileiro de Geofísica, Brasília, 14 a 17 de novembro de 2010. Seu conteúdo foi revisado pelo Comitê Técnico do IV SimBGf, mas não necessariamente representa a opinião da SBGf ou de seus associados. É proibida a reprodução total ou parcial deste material para propósitos comerciais sem prévia autorização da SBGf.

\section{Resumo}

A determinação da velocidade das interfaces geológicas através de dados sísmicos constitui uma etapa básica para imageamento sísmico do arcabouço estrutural em subsuperfície. A qualidade do resultado da migração préempilhamento é em grande parte dependente da estimativa do Campo de velocidade.

O presente trabalho tem como objetivo propor, através do reprocessamento da linha sísmica 0204-RL-239, o estudo da análise de velocidade PSTM das ondas primárias nas interfaces geológicas da bacia sedimentar mesozóica do Tacutu e identificar estruturas geológicas e a presença e a eliminação de eventos indesejáveis, como ruídos, múltiplas e refrações, que muitas vezes se propagam até a migração, possibilitando no final a interpretação sísmica do dado migrado identificando as principais formações que compõem a estratigrafia da bacia em questão.

\section{Introdução}

A Bacia do Tacutu é um depósito sedimentar formado por sistema de grábens, situada na fronteira do estado brasileiro de Roraima com o distrito guianense de Rupununi, em uma região dominada pelo Cinturão da Guiana Central. Originou-se por um rifteamento ativo que evoluiu para um rifteamento passivo, oblíquo, fortemente controlado por antigas linhas de fraqueza no embasamento (EIRAS e KINOSHITA, 1988).

$\mathrm{Na}$ década de 80 foram realizados alguns estudos naquela bacia para se saber o seu potencial petrolífero trouxe informações inéditas sobre a geologia daquela região que permitem interpretar, com relativa segurança, a evolução geológica do Gráben do Tacutu. Entretando, apesar das informações adquiridas, ainda persistem alguns pontos conflitantes ou obscuros quanto à estratigrafia da bacia (EIRAS e KINOSHITA,1990).

A determinação precisa das velocidades das interfaces geológicas numa bacia terrestre é uma etapa básica, porém complicada, para o imageamento sísmico do arcabouço estrutural em subsuperfície. A análise de velocidade se torna algo complexo quando relacionado a dados sísmicos terrestre, pois nesses ocorrem contaminação do dado por ruídos e também são afetados pela problemática da estática.

O presente trabalho propõe a análise de velocidade PSTM como uma técnica eficiente na melhorar do dado sísmico da Bacia do Tacutu, facilitando o imageamento e o intendimento do arcabouço estrutural.

\section{Metodologia/ Problema Investigado}

A metodologia adotada para o melhoramento da seção sísmica da Bacia do Tacutu se deu através da atenuação do ruído sempre aliado a análise espectral como controle de qualidade, aplicação de uma boa solução de estática de refração.

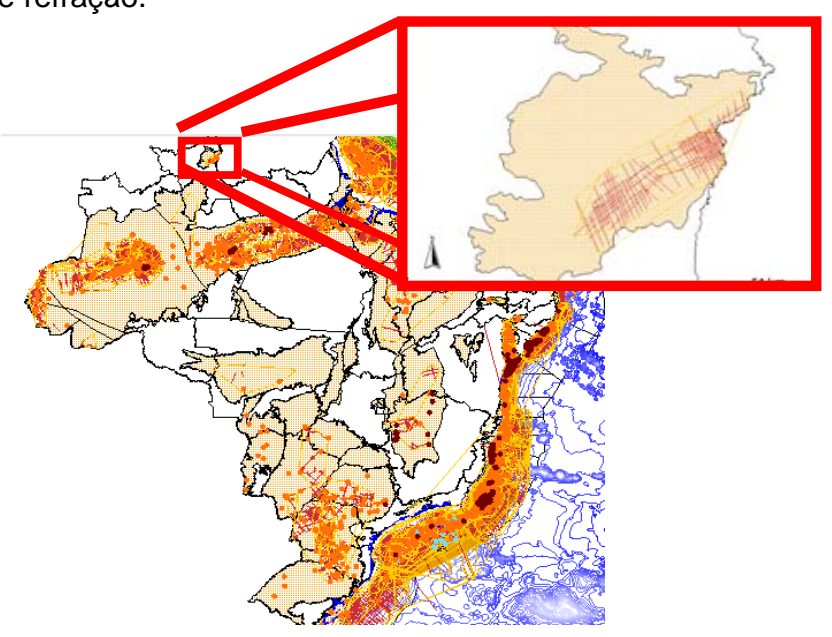

Figura 1 - Mapa de localização da Bacia do Tacutu com todas as linhas sísmicas de reflexão plotadas.

O método de análise de velocidade PSTM tem como objetivo reduzir a presença de ruídos coerentes e incoerentes aumentando a razão sinal/ruído.

A metodologia aplicada no presente trabalho teve o auxílio de análise espectral das formações geológicas que se mostram presentes na linha 0204-RL-239, sendo estas Fomações Manari/Apoteri, Pirara e Tacutu. Pois essa análise espectral serviu para avaliarmos o quanto o dado estava sendo contaminado por ruídos de altas e baixas frequências.

Por se tratar de uma bacia terrestre, onde o grau de complexidade no processamento de dados sísmicos aumenta significativamente, após duas análises de velocidades convencionais a primeira com intervalo de cdp de 80 em 80 e a segunda de 40 em 40. Para realizar a análise de velocidade PSTM foi preciso migrar o dado antes do empilhamento. Após a migração do dado 
sísmico é necessário reorganizar o dado, para se fazer uma nova análise de velocidade, porém com algumas ressalvas, pois antes cada CDP era representado 48 vezes (cobertura), no entanto após tê-lo migrado se faz necessário a multiplicação deste dado pelo número de traços migrados para representar um único $C D P$, que neste caso foram utilizados 7 totalizando uma cobertura de 336 .

Nas primeiras análises de velocidade a identificação das interfaces representadas nos gathers era dificultada pela expressiva contaminação do dado por ruídos desfavorecendo assim a razão sinal/ruído.

\section{Resultados}

A partir dessa metodologia aplicada combinada com ferramentas sofisticadas de processamento sísmico observa-se como resultado uma seção sísmica de boa qualidade.

A fase de análise de velocidade se demonstrou uma etapa muito importante no processamento sísmico, em especial, de dados de bacias terrestres. É importante ressaltar aqui que aliada a análise de velocidade, a análise espectral e teste de filtros de freqüências tiveram papéis fundamentais no que se referem aos tratamentos dos dados sísmicos da bacia do Tacutu, pois papéis estes que asseguraram as aplicações corretas de algumas ferramentas que manipulam a freqüência do dado, como TV Spectral Whitening, esta ferramenta tem como objetivo aplicar um certo ganho de frequência para várias bandas.

A prova que a metodologia aplicada no reprocessamento da linha 0204-RL-0239 alcançou p resultado desejado é possível ver na figura 2 e 3 onde na primeira é possível ver a presença de refletores e na segunda sendo possível identificar uma zona sem reflexão aparente a qual sugere-se que seja área de borda da bacia com uma "paredão".

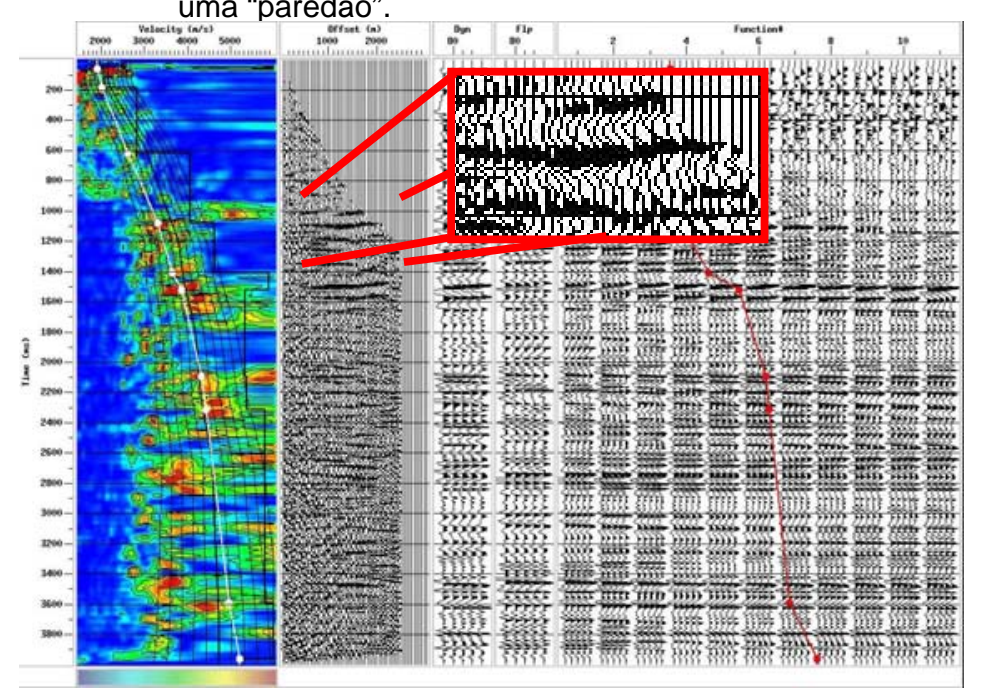

Figura 2 - Linha 0204-RL-0239 durante a análise de velocidade PSTM, nesta é possível identificar sem grandes dificuldades a presença de refletores.
O padrão de configuração paralela ondulada das reflexões sísmicas identificada nas análises de fácies na linha 0204-RL-0239, indicando uma formação de estruturas, provavelmente, na fase posterior ao desenvolvimento do rifte. Com isto concorda-se com a teoria proposta por Eiras \& Kinoshita (1990), no qual eles defendem que o Gráben do Tacutu sofreu um evento transcorrente no Pliomioceno, resultante da convergência das placas de Cocos, Nazca e do Caribe com a placa Sul-Americana

\section{Discussão e Conclusões}

O processamento sísmico, com ênfase nas análises de velocidades convencionais e após o dado migrado, possibilitou alcançar os objetivos propostos, visto que foi produzida seção sísmica de qualidade satisfatória à interpretação. Ela nos permite identificar refletores que podem estar associados às estruturas geológicas em subsuperfície. Essas estruturas representam pulsos magmáticos, que no poço 1-TU- 1-RR podem ser contados 18 pulsos magmáticos nos $385 \mathrm{~m}$ de basalto perfurados (Eiras,1990), intercalados com camadas sedimentares como silttos.

A ausência de reservatórios arenosos não condiz com a maior parte das bacias do tipo rifte existente no mundo e por isso, torna-se essencial a construção de seções sísmicas de melhor qualidade, capazes de contribuir ao conhecimento geológico. Com intuito de melhorar a qualidade das imagens sísmicas geradas, diversos trabalhos vêm sendo realizados empregando metodologias de processamento mais sofisticadas ou não convencionais aos dados sísmicos da região.

Por conta disso, recomendamos a construção de um modelo de velocidade correlacionada com os dados de poços capaz de descrever em uma escalar menor o comportamentos das velocidades sísmicas dentro das interfaces estudadas, para melhorar a interpretação da mudança de comportamento de propagação das ondas nos diferentes contatos geológicos. Além disso, sugerimos a utilização de migrações em profundidade, capazes de admitir variações laterais de velocidade, sobretudo nas linhas de direção NW-SE, para melhorar o imageamento de subsuperfície. Concluindo, Sugerimos um adensamento de linhas sísmicas naquela bacia como uma nova aquisição com 3D de maneira a identificar com mais precisão os reais rservatório, e com as informações de poços da área. Com estes novos estudos, o comportamento da velocidade poderá ser avaliado com um maior critério e uma área maior, possibilitando assim uma boa avaliação no que se refere ao potencial petrolífero da bacia do Tacutu. 


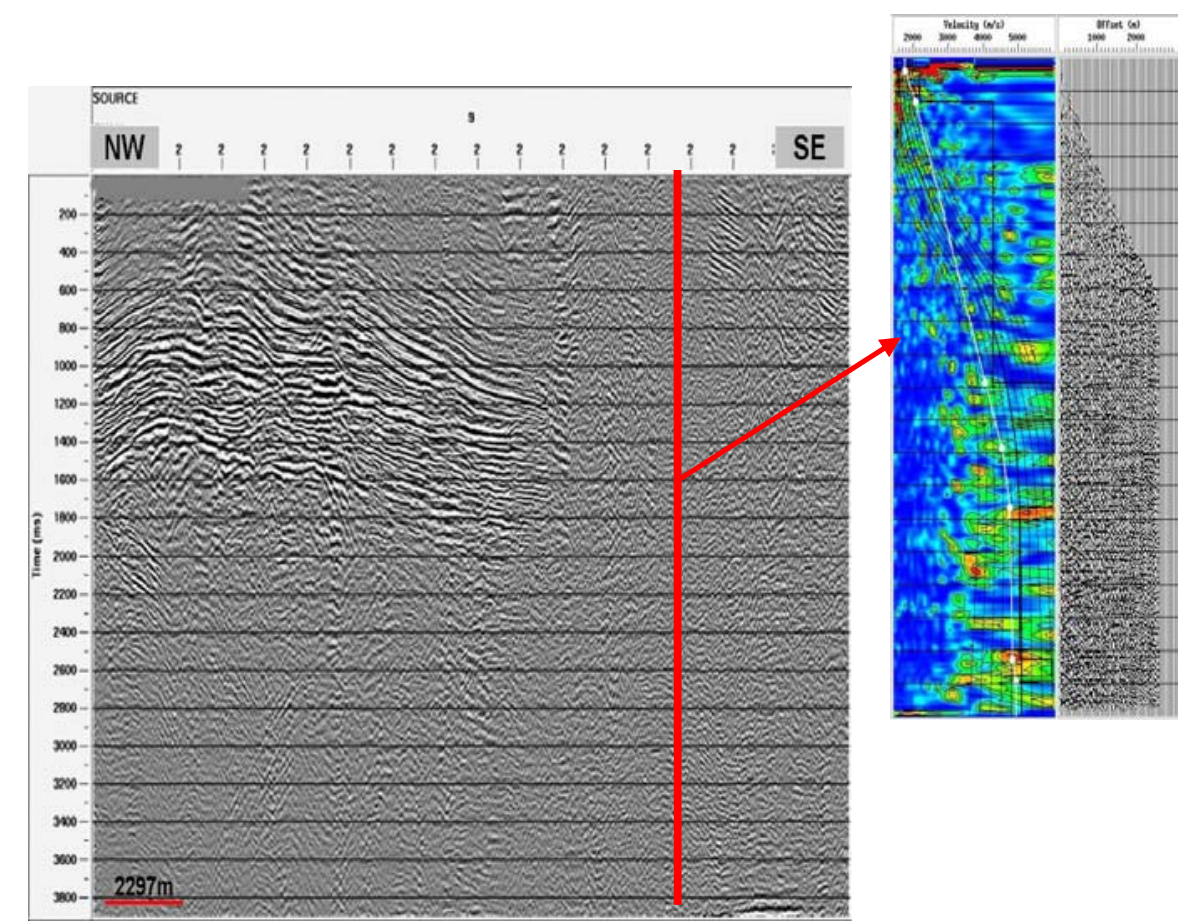

Figura 3: Linha 0204-RL-0239 com o semblance indicando e que a análise está passando no momento pó um embasamento acústico.

\section{Agradecimentos}

Agradeço aos professores da Universidade Federal Fluminense que possibilitou a realização deste trabalho no projeto de curso de graduação e a ANP por ceder os dados.

\section{Referências}

EIRAS, J. F. e KINOSHITA, E. M. (1990) - Geologia e perspectivas petrolíferas da Bacia do Tacutu, In: Origem e Evolução das Bacias Sedimentares, Rio de Janeiro, PETROBRÁS, Anais, pp. 197-220.

EIRAS, J. F. e KINOSHITA, E. M (1988) - Evidências de monvimentos transcorrentesna Bacia do Tacutu, In: seminário sobre riftes intracontinentais, 1, rio de Janeiro, PETROBRAS/DEPEX, Anais, pp. 106-139.

EIRAS, J. F. et al. (1994) - Estratigrafia das bacias sedimentares do Brasil. 1987 .Boletim de Geociências da PETROBRAS, vol.8, n.1, p. 197-45, jan-mar.

FARIA, E. L. Migraçao antes do empilhamento utilizando a propagação reversa no tempo. 1986. 111f. Dissertação( Mestrado em Geofísica)- Universidade Federal da Bahia, Instituto de geociências, Salvador, 1986.

OROGODNIK, F. S. (2007). Processamento de dados sísmicos da bacia do Tacutu utilizando as migrações de Kirchhoff pós e pré-empilhamento. Belém-PA, Monografia (graduação em Geofísica)- UFPA. 


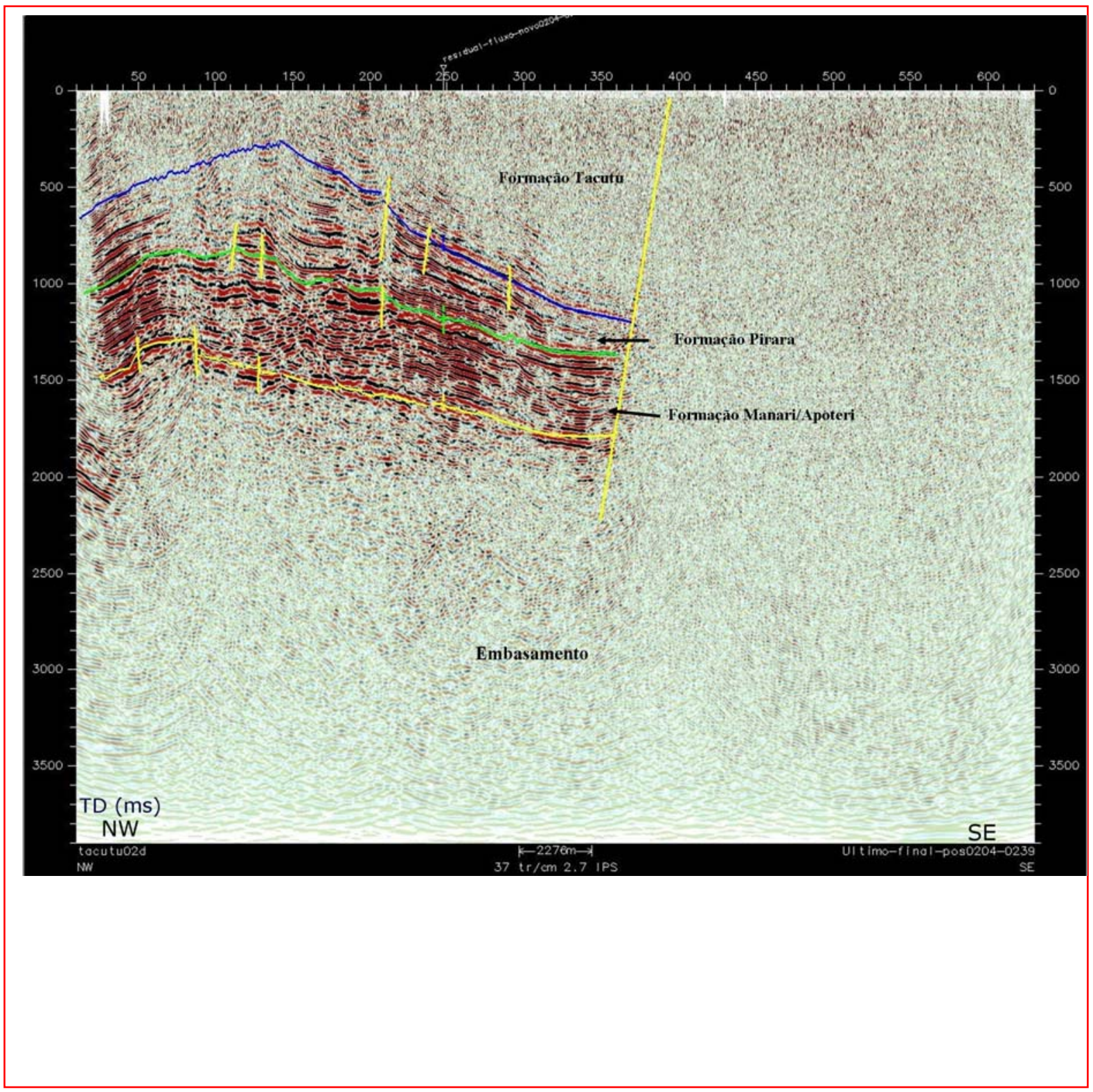

Figura 4 - Interpretação da linha sísmica 0204-RL-0239 no software de interpretação após a migração final. 